\title{
An Experimental Examination of Customer Preferences on User Interface Design of Mobile Services
}

\author{
Heejun Park ${ }^{1}$ and Seung Baek ${ }^{2}$ \\ ${ }^{1}$ Department of Information and Industrial Engineering, Yonsei University, \\ 134 Shinchon-Dong, Seodaemoon-Gu, Seoul 129-749, Rep. of Korea \\ h.parkeyonsei.ac.kr \\ ${ }^{2}$ Division of Business Administration, Hanyang University, \\ 17 Haengdang-Dong, Seongdong-Gu, Seoul 13-791, Rep. of Korea \\ sbaek@hanyang.ac.kr
}

\begin{abstract}
Designing mobile services is fundamentally different from designing online services. Not only are there differences in underlying technologies, but also in the way people use the services. If these differences are not taken into account, mobile services are likely to fail. However, it is quite difficult to provide a singlelayered user interface in a small screen. This study aims at examining how design attributes of user interfaces of mobile services affect customer preferences. In order to explore customer preferences to each design attribute of mobile services, we measure and analyze customer's WTP (Willingness To Pay) toward their different interface designs. Ultimately, throughout the study, we try to answer how to design mobile services in small screen of mobile devices. In addition, we propose an optimal design solution that customers likely prefer.
\end{abstract}

Keywords: User Interface(UI), Willingness To Pay(WTP), Mobile Services.

\section{Introduction}

The Internet has provided an efficient and effective way of delivering information and services to millions of users who are connected to a wired network since it has been introduced. However, this wired network addresses two major constraints: time and place. These limitations have raised the issue of the mobile Internet, which enables users to access information from any place at any time. Recently, the population of using mobile Internet has been growing due to the widespread use of mobile devices and highspeed Internet services. Mobile technology, however, is still very much in its infancy regarding usability, display capabilities and computing performance. Thus, the main usage of mobile Internet is concentrated on ring/avatar downloads. For mobile Internet services to be propagated, they need to provide more intuitive and rich interface as well as contents of them. However, as the size of mobile devices has become smaller, it is quite difficult to provide intuitive and rich interface for users' conveniences [7].

This study aims at exploring customer preferences to user interface design attributes. We measure customer's WTP (Willingness To Pay) toward different interface design options. Ultimately, the study tries to answer how to design user interface of mobile services in small screen of mobile devices to satisfy users. 


\section{User Interface of Mobile Services}

The user interface and the size of mobile devices are the main concerns in designing mobile services. A well designed single-layered user interface will be more user friendly than the conventional one and it will be having edge over others. However, it is quite difficult to provide a single-layered user interface in a small screen. Designing mobile services is fundamentally different than designing online services in the Internet. Not only are there differences in underlying technologies, but also in the way people use services. If these differences are not taken into account, mobile services are likely to fail. If mobile services do not deliver users' needs with their convenience, these services will fail no matter how excellent the underlying technology is. Designing usable interfaces for tomorrow's mobile devices is not trivial but involves a series of challenges on Human Computer Interaction(HCI). Mobile services require efficient ways to record and access information under the circumstances that are often quite different from those where desktop computers are used. Displays on mobile devices are small, means of input are limited and use-contexts are very dynamic. The usability of mobile services consequently suffers from interfaces being very compact and cluttered with information, demanding the user's full attention. Many people say that mobile services are not yet attractive and usable for customers. There clearly is a lack of understanding of real user needs and how mobile internet can help users satisfy those needs.

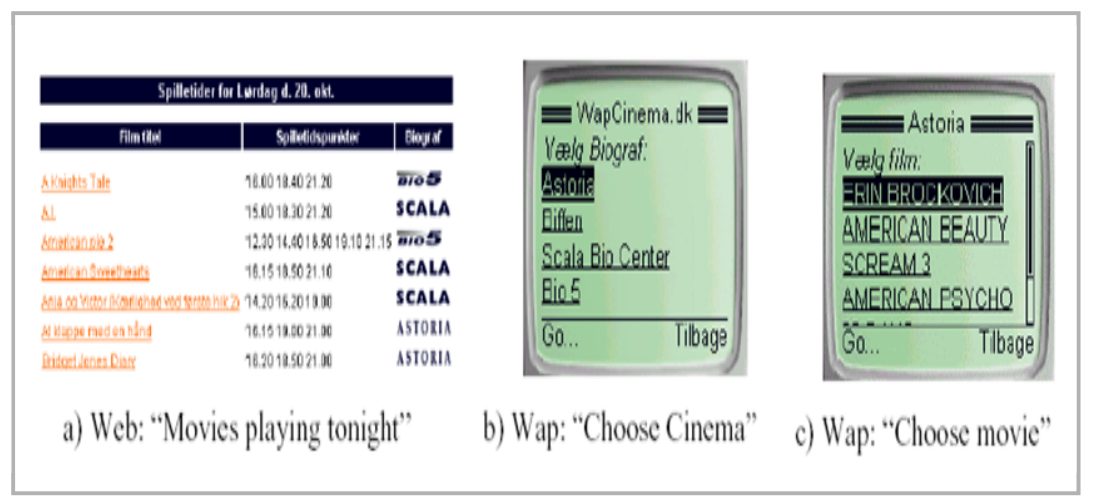

Fig. 1. Web Interface and Mobile Interface

Wireless Application Protocol (WAP) phones are a growing relevant part of the mobile market, and the number of WAP services offered is rapidly increasing. However, usability is crucial for these services which must be easily operated on small screens and keyboards. One of the reasons that many WAP sites have failed is that many service providers simply tried to carry their websites over to the mobile Internet. This shows that little thought has been given to the characteristics of mobile Internet and to the specific needs of people who use their mobile devices in real life. Understanding the fundamental differences between mobile and the web is essential for the success of mobile services [7]. Figure 1 compares a web interface with a mobile interface. Using the web site, users view all relevant information in one page. Whereas, accessing the 
services from WAP-based phones, users require a lot of clicking in a pre-defined sequence, due to the division of information into a large number of sub-pages. By following sequential menus, users can find specific mobile services. Generally, interfaces of WAP-based mobile services require minimal attentions and interactions. The usability of mobile services consequently suffers from interfaces being very compact and cluttered information. It is crucial to design the menus which can get the user's full attention, remaining simple and the required interaction minimal [9].

\section{Willingness to Pay(WTR) for Mobile Services}

Willingness to Pay(WTP) is defined as the maximum monetary amount that an individual would pay to obtain a good or service [1]. It is crucial in estimating the demand curves and determining optimal pricing schedules. The WTP has focused on cognitive structure of customer to specific tangible or intangible goods under experimental environment [8][10]. It is widely used to provide information to policy makers, regarding the economic value of non-market or non-pecuniary environmental assets. In this study, by measuring WTP for various interface designs, we try to investigate what features of interface design attributes affect customers' WTP [2][3].

To measure WTP, there are two methods: contingent method and conjoint method. In the contingent method, arbitrary goods or service are presented with specific prices, and then respondents take or reject the offers. While the contingent method asks respondents to evaluate real products, the conjoint method asks them to evaluate hypothetical products. The conjoint method allows researchers to presents respondents with a choice set that contains several alternatives that vary along several attributes, including price [5]. Respondents decide the rankings among the alternatives. Based on the rankings, researchers can analyze the preferences and utilities of respondents for specific goods/service.

\section{Research Methodology and Hypothetical Products}

In order to analyze the impacts of specific attributes on customers' preferences, this study employs conjoint analysis(shown on Figure 2) which shows relative importance of various utilities considered by consumers when they purchase service and suggests a service that consists of the most ideal combination of those utilities [5]. Analyzing relative impacts of interface design attributes, we are identifying the influencing factors that affect customers' WTP throughout focus group interview.

Its result shows four design attributes which are the information about service type, payment and recommendation to the use of specific mobile services shown in the menu and its structures and three attributes level for each design attribute as shown in Table 1.

With three attributes and four levels for each attributes, $81(3 * 3 * 3 * 3)$ hypothetical products could be generated. All 81 possible hypothetical products are reduced to nine (shown in Table 1) based on a fractional factorial design due to the difficulty in surveying with all 81 questions [11]. In order to measure customer preferences to each of nine hypothetical products, the study employs the rank-order method, rather than the rating method. 116 respondents are asked to provide the maximum monetary amounts that they would pay to get these products. Based on the amounts, we investigate how much each menu design attribute of mobile services affects customer's WTP. 


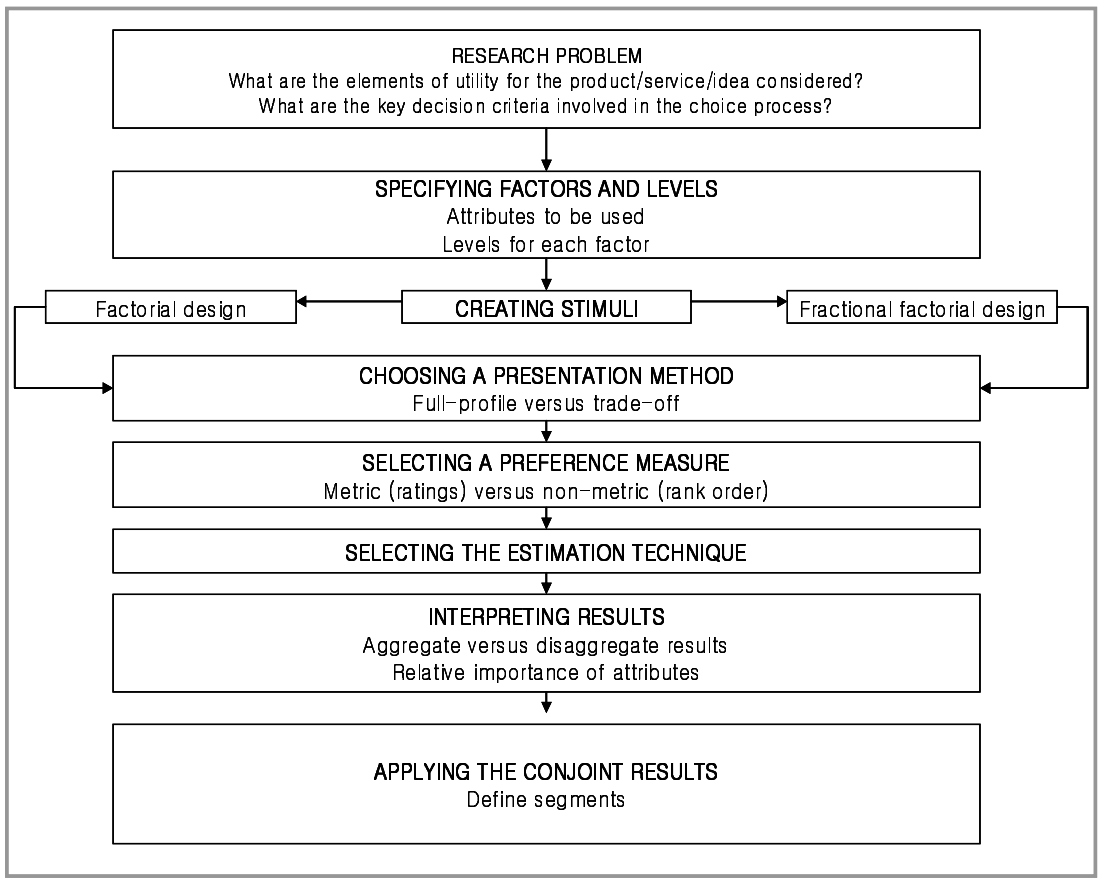

Fig. 2. Research model to conjoint analysis

Table 1. Hypothetical Products

\begin{tabular}{|c|c|c|c|c|}
\hline $\begin{array}{l}\text { Prod } \\
\text { uct }\end{array}$ & $\begin{array}{l}\text { Mobile Service } \\
\text { Type }\end{array}$ & $\begin{array}{r}\text { Payment } \\
\text { Information }\end{array}$ & $\begin{array}{r}\text { Menu Position } \\
\text { of Mobile Service }\end{array}$ & $\begin{array}{l}\text { Recommendation } \\
\text { Information }\end{array}$ \\
\hline P1 & No Information & No Information & First Line & $\begin{array}{c}\text { User Evaluation } \\
\text { Based Recommendation }\end{array}$ \\
\hline P2 & Entertainment & Coupon & Middle Line & $\begin{array}{l}\text { User Evaluation } \\
\text { Based Recommendation }\end{array}$ \\
\hline P3 & No Information & Cash Discount & Middle Line & No Information \\
\hline P4 & $\begin{array}{c}\text { Information } \\
\text { /Communication }\end{array}$ & Cash Discount & Second Line & $\begin{array}{l}\text { User Evaluation } \\
\text { Based Recommendation }\end{array}$ \\
\hline P5 & $\begin{array}{c}\text { Information } \\
\text { /Communication }\end{array}$ & No Information & Middle Line & $\begin{array}{l}\text { Log Data Based } \\
\text { Recommendation }\end{array}$ \\
\hline P6 & Entertainment & Cash Discount & First Line & $\begin{array}{l}\text { Log Data Based } \\
\text { Recommendation }\end{array}$ \\
\hline P7 & Entertainment & No Information & Second Line & No Information \\
\hline P8 & $\begin{array}{c}\text { Information } \\
\text { /Communication }\end{array}$ & Coupon & First Line & No Information \\
\hline P9 & No information & Coupon & Second Line & $\begin{array}{l}\text { Log Data Based } \\
\text { Recommendation }\end{array}$ \\
\hline
\end{tabular}


The focus of conjoint analysis is to explore customer preferences for product attribute levels and the customer benefits that may flow from the product attributes [6]. In addition, it allows us to measure part-worth functions at the individual level. Hence, if preference heterogeneity is present, by using cluster analysis, we can identify groups that have distinct preferences.

\section{Results and Discussion}

We interviewed 116 respondents consisting of 53 males and 63 females and most of them consist of 12-19 year olds in this study. In addition to portraying the impact of each level (entertainment, information / communication, no information et. al.) with the part-worth estimates, conjoint analysis can assess the relative importance of each design factor (information about mobile service type, payment of mobile service, position of mobile service, and recommendation to mobile service). Since the part-worth estimates are on a common scale, the greatest contribution to overall utility of preference, and hence the most important factor, is the factor with the highest range of part-worth.

The focus of conjoint analysis is to explore customer preferences for product attribute levels and the customer benefits that may flow from the product attributes. In addition, it allows us to measure part-worth functions at the individual level. Hence, if preference heterogeneity is present, by using cluster analysis, we can identify groups that have distinct preferences [5].

In this study, we examine the relative impacts of menu design attributes of mobile services on customer's WTP. We try to find an optimal menu design of mobile services that high-valued by users. Table 2 reports the means of the part-worth and relative importance for 116 subjects. The greater the relative importance, the more an attribute influences your preferences for mobile services. If the information about mobile service types is shown in menu, there is the highest possibility that customers purchase mobile services $(27.51 \%)$. In other words, customers utilize information about mobile service types as critical information in purchasing of mobile services. The second influential menu design attribute is the payment information of mobile services shown in menu, $(26.53 \%)$, the third is the positions of mobile services within menu $(23.21 \%)$, and the last is recommendation information $(22.75 \%)$. Based on the result, we can say that the understanding customers are the most important factor in terms of menu design. Many companies pay a lot of money to locate their services in higher positions in the menu, or use recommendation information to sell their services. Based on our study, we found that mobile customers tend to be more sensitive to services themselves, rather than the artificial information, such as recommendation information or menu positions.

In terms of part-worth for the mobile service types, customers prefer entertainment mobile services to other services. This result proves the actual usages of mobile Internet. Many users tend to use entertainment services, rather than other types of mobile services. In terms of payment information, customers prefer the mobiles service shown its cash discount information in the menu. When they use a specific mobile service, their decisions heavily depend on the payment information, especially on cash discount information. Regarding to recommendation information about mobile services, customers prefer the mobile service marked "Strongly Recommended" in the menu. Normally, service 
operators mark specific mobile services as "Strongly Recommended", when the services are popular and new. "Hit" marks are less attractive for customers than "No Information". In terms of menu position, customers are likely to purchase a mobile service in the middle line, rather than the second line or the first line. The relative importance of design attributes will guide the menu design of mobile services. The result shows that, for identical services, their different menu designs affect customer's purchasing power.

Table 2. Part-Worth and Relative Importance

\begin{tabular}{|c|c|c|c|c|}
\hline \multirow{2}{*}{ Attribute } & \multicolumn{3}{|c|}{ Part-Worth } & \multirow{2}{*}{$\begin{array}{c}\text { Relative } \\
\text { Importance } \\
(\%)\end{array}$} \\
\hline & 1 & 2 & 3 & \\
\hline \multirow{2}{*}{$\begin{array}{l}\text { Mobile Service } \\
\text { Type }\end{array}$} & Entertainment & $\begin{array}{c}\text { Information } \\
\text { /Communication }\end{array}$ & No Information & \multirow{2}{*}{27.51} \\
\hline & 1.74 & 0.32 & 0.94 & \\
\hline \multirow{2}{*}{$\begin{array}{l}\text { Payment } \\
\text { Information }\end{array}$} & Discount & Coupon & No Information & \multirow{2}{*}{26.53} \\
\hline & 1.54 & 0.96 & 0.50 & \\
\hline \multirow{3}{*}{ Menu Position } & First Line & Second Line & Middle Line & \multirow{3}{*}{23.21} \\
\hline & & & & \\
\hline & 1.20 & 0.48 & 1.33 & \\
\hline \multirow{2}{*}{$\begin{array}{l}\text { Recommendation } \\
\text { Information }\end{array}$} & $\begin{array}{l}\text { Log Data Based } \\
\text { Recommendation }\end{array}$ & $\begin{array}{c}\text { User Evaluation } \\
\text { Based }\end{array}$ & No Information & \multirow{2}{*}{22.75} \\
\hline & 0.85 & 1.16 & 0.99 & \\
\hline
\end{tabular}

As result of this analysis Table 2 reports the means of the part-worth and relative importance for 116 subjects. In terms of part-worth for the mobile service types, customers prefer entertainment mobile services to other services. This result proves the actual usages of mobile Internet. Many users tend to use entertainment services, rather than other types of mobile services. In terms of payment information, customers prefer the mobiles service shown its cash discount information in the menu. When they use a specific mobile service, their decisions heavily depend on the payment information, especially on cash discount information. Regarding to recommendation information about mobile services, customers prefer the mobile service marked "Strongly Recommended" in the menu. Normally, service operators mark specific mobile services as "Strongly Recommended", when the services are popular and new. "Hit" marks are less attractive for customers than "No Information". In terms of menu position, customers are likely to purchase a mobile service in the middle line, rather than the second line or the first line. The relative importance of design attributes will guide the menu design of mobile services. The result shows that, for identical services, their different menu designs affect customer's purchasing power.

One of the most common uses of conjoint analysis is to group respondents with similar part-worths or importance values to identify segments. Because of the following reasons, conjoint analysis can be used as a useful method for implementing market segmentation and product positioning [4]. Based on 116 respondents, the study 
identifies three mobile service customer groups. Three clusters consist of 52, 28, and 36 respondents. In this study, we are to do cluster analysis as shown in Table 3.

In terms of mobile service types, respondents in three clusters have a similar preference structure. All of them give a significant preference to entertainment mobile services. However, regarding to payment information, menu position, and recommendation information, respondents in three clusters have different preferences. Respondents in cluster 1 prefer the mobile service shown cash discount information, located at the middle line, and marked as "Strongly Recommended" in the menu. Respondents in cluster 2 prefer the mobile service located at the second line in the menu position and marked as "Hit" in the menu. Unlike respondents in other two clusters, they do not seriously consider the payment information when they choose a specific mobile content. Respondents in cluster 3 prefer the mobile service shown coupon information and located at the first line in the menu. Unlike respondents in other two clusters, they do not seriously consider the recommendation information when they choose a specific mobile content. Respondents in cluster 2 and in cluster 3 have totally different preferences. While the cluster 2 regards the recommendation information as a critical factor in buying a mobile service, it does not seriously consider payment information in buying a mobile service. The cluster 3 seriously considers payment information, not payment information.

Table 3. Cluster Analysis

\begin{tabular}{ccccc}
\hline Attribute & Item & \multicolumn{3}{c}{ Cluster } \\
& & Cluster 1 & Cluster 2 & Cluster 3 \\
\hline \multirow{2}{*}{ Mobile service type } & Entertainment & $\mathbf{0 . 4 5}$ & $\mathbf{1 . 7 0}$ & $\mathbf{0 . 4 1}$ \\
& Information/communication & -0.87 & -0.45 & -0.57 \\
No information & 0.42 & -1.25 & 0.17 \\
Payment & Discount & $\mathbf{1 . 1 6}$ & -0.02 & 0.08 \\
information & Coupon & -0.81 & -0.57 & $\mathbf{1 . 4 7}$ \\
& No information & -0.35 & $\mathbf{0 . 6 0}$ & -1.56 \\
Menu position of & First line & -0.01 & -0.17 & $\mathbf{0 . 7 9}$ \\
mobile service & Second line & -1.13 & $\mathbf{0 . 1 5}$ & -0.19 \\
& Middle line & $\mathbf{1 . 1 5}$ & 0.01 & -0.59 \\
Recommendation & Log data & -0.71 & $\mathbf{0 . 3 5}$ & 0.28 \\
information about & User evaluation & $\mathbf{1 . 1 0}$ & -0.07 & -1.01 \\
mobile service & No information & -0.39 & -0.27 & $\mathbf{0 . 7 3}$ \\
\hline
\end{tabular}

Due to the small screens of mobile devices, the amount of information shown in the menu is minimal. Therefore, mobile service designers try to find out the condensed information that can catch customer's eyes. Some, like cluster 2, are sensitive to payment information shown in the menu. Others, like cluster 3 , are sensitive to recommendation information shown in the menu. The result states the need to personalize the menu design for mobile services, as well as to personalize the mobile services. 
One of the most common uses of conjoint analysis is to group respondents with similar part-worths or importance values to identify segments. Based on 116 respondents, the study identifies three mobile service customer groups as shown in Table 3. In terms of mobile service types, respondents in three clusters have a similar preference structure. All of them give a significant preference to entertainment mobile services. However, regarding to payment information, menu position, and recommendation information, respondents in three clusters have different preferences.

The results of this study provide a theoretical understanding of customers' preferences on user interface design of mobile internet services. The important user interface design attributes and the customer segments of mobile internet services revealed by this study

\section{Conclusions and Recommendations}

One often meets the argument that due to the complexity of the service model and the convergence of technologies and services expected in mobile services, it is very little relevant research available to help us understand the mobile services and their users. The main purpose of the study is to explore attributes that influence customers' preferences to mobile services. To explore the relative importance of the attributes, the study uses conjoint analysis. It finds that the most influential attribute is the mobile service types. This finding supports the current phenomenon that the main usage of mobile services is concentrated on entertainment services. Although this study tries to understand customers of mobile services empirically, it has very limited contributions to theoretical development. In addition, regarding to the relationships between attributes of mobile services and customers' preferences, it does not provide a theoretical explanation. However, the study helps us to understand mobile customers.

\section{References}

1. Brown, T.C., Gregory, R.: Why the WTA-WTP disparity matters. Ecological Economics 28, 323-335 (1999)

2. Cameron, T.A., James, M.D.: Estimating Willingness to Pay from Survey Data: An Alternative Pre-Test-Market Evaluation Procedure. Journal of Marketing Research 24, 389-395 (1987)

3. Gil, J.M., Gracia, A., Sanchez, M.: Market Segmentation and Willingness to Pay for Organic Products in Spain. International Food. and Agribusiness Management Review 3, 207-226 (2000)

4. Green, P.E., Krieger, A.M.: Segmenting Markets with Conjoint Analysis. Journal of Marketing, pp. 20-31 (1991)

5. Green, P.E., Srinivasan, V.: Conjoint Analysis in Consumer Research: Issues and Outlook. Journal of Consumer Research 5, 103-123 (1978)

6. Green, P.E., Srinivasan, V.: Conjoint Analysis in Marketing: New Developments with Implications for Research and Practice. Journal of Marketing 54, 3-19 (1990)

7. Hair, J.K., Rolph, J.R., Anderson, E., Tatham, R.L., Black, W.C.: Multivariate data analysis. Prentice Hall, Inc., Englewood Cliffs (1999) 
8. Shefrin, H., Caldwell, D.: Determinants of the Magnitude of Willingness to Accept Relative to Willingness to Pay. Journal of Behavioral Decision Making 14, 87-105 (2001)

9. Walker, M.E., Morera, O.F., Vining, J., Orland, B.: Disparate WTA-WTP Disparities: The Influence of Human Versus Natural Causes. Journal of Behavioral Decision Making 12, 219-232 (1998)

10. Wertenbroch, K., Skiera, B.: Measuring Consumers Willingness to Pay at the Point of Purchase. Journal of Marketing Research, pp. 228-241 (2002)

11. Wittink, D.R., Cattin, P.: Commercial Use of Conjoint Analysis: An Update. Journal of Marketing 53, 81-86 (1989) 